\title{
Additive Manufacturing of SiC Ceramics with Complicated Shapes Using the FDM Type 3D-Printer
}

\author{
Hisaya Masuda, Yoshio Ohta, Mikito Kitayama \\ Department of Life, Environment and Materials Science, Graduate School of Engineering, \\ Fukuoka Institute of Technology, Fukuoka, Japan \\ Email: kitayama@fit.ac.jp
}

How to cite this paper: Masuda, H., Ohta, Y. and Kitayama, M. (2019) Additive Manufacturing of SiC Ceramics with Complicated Shapes Using the FDM Type 3D-Printer. Journal of Materials Science and Chemical Engineering, 7, 1-12.

https://doi.org/10.4236/msce.2019.72001

Received: December 30, 2018

Accepted: February 23, 2019

Published: February 26, 2019

Copyright $\odot 2019$ by author(s) and Scientific Research Publishing Inc. This work is licensed under the Creative Commons Attribution International License (CC BY 4.0).

http://creativecommons.org/licenses/by/4.0/

\begin{abstract}
Silicon carbide $(\mathrm{SiC})$ ceramics have excellent properties and widely used for high temperature applications. So far, joining techniques have been applied to fabricate large $\mathrm{SiC}$ ceramics with complicated shapes. In this work, the additive manufacturing (AM) technique was examined to fabricated $\mathrm{SiC}$ ceramics with complicated hollow structures using the Fused Deposition Modeling (FDM) type 3D-printer. To mold the hollow structure for the applications such as heat exchangers, the "support-less" condition must be achieved. Thus, extruded SiC-phenol resin compounds must be cured immediately after molding to keep the molded shapes. To increase the thermal conductivity of the $\mathrm{SiC}$ compounds, the combinations of commercial SiC powders with different average diameters were examined for increasing the volume fraction of $\mathrm{SiC}$ particles to the phenol resin. $\mathrm{SiC}$ compounds with optimized rheological properties for the modified FDM-type 3D-printer were successfully obtained.
\end{abstract}

\section{Keywords}

Additive Manufacturing, 3D-Printer, FDM, Ceramics, SiC

\section{Introduction}

Silicon Carbide $(\mathrm{SiC})$ ceramics for high temperature and wear-resistant applications have steadily increased due to their excellent properties such as high chemical and thermal resistance, high wear resistance, high stiffness, high thermal conductivity, low thermal expansion, and low density [1]. In general, ceramics are produced through a series of processing such as mixing the raw mate- 
rials, molding and sintering. When large and/or complicated shapes are needed, several parts are separately sintered, and then joined together. $\mathrm{SiC}$ ceramics have been fabricated through the solid-state sintering, liquid-phase sintering or reaction-sintering processes using the pressureless-sintering or hot-pressing methods. Especially, the reaction sintering has advantages over the other methods, because it could make dense sintered bodies at relatively low temperature and could be sintered "near net shape" [2] [3].

With the development of the Additive Manufacturing (AM) technology, the moldings of resin and metal have been followed by those of ceramics. Ceramic manufacturing using the AM technology would have several advantages because it uses no molds and complicated shapes such as the hollow structures would be easily fabricated, and moreover, it could integrally mold composite materials. Thus, it is highly expected to be applied in the aerospace, medical and automobile fields [4].

Molding $\mathrm{SiC}$ powder has been investigated using the powder-based 3D-printing (P-3DP) and the slurry-based 3D-printing (S-3DP) techniques [5] [6]. For example, it was reported that the reaction-sintering $\mathrm{SiC}$ ceramics was fabricated by molding a compound containing SiC powder using the P-3DP technique, and subsequently infiltrating the molded body with molten $\mathrm{Si}$ [7]. However, there have been much less works regarding the fabrication of ceramics using the Fused Deposition Modeling (FDM) type 3D-printer, which has been widely spreading commercially due to its low cost, easy handling and installation.

In this research, the FDM-type 3D-printers have been used to fabricate $\mathrm{SiC}$ ceramics with the complicated shapes. The FDM-type 3D-printers generally require the resin filaments that melt at the nozzle, and are deposited on the bed [8]. Since the resin compound containing SiC powders would be extremely hard, it would be almost impossible to mix them using the kneader. Thus, a modified FDM-type 3D-printer that uses the resin slurry containing $\mathrm{SiC}$ powder instead of the filament has been developed in this work. This type of 3D printer was called as the "Robocasting Technology" [9], which usually uses water as liquid medium, and the volume fraction of solid was extremely low to obtain low enough viscosity for molding [10]. In this work, phenol resin is selected as binder because its carbon content is the highest among the commercially available resins. The molded bodies are de-waxed by heating in an inert atmosphere to form the mixture of $\mathrm{SiC}$ and carbon powder, which reacts with molten $\mathrm{Si}$ to form dense $\mathrm{SiC}$ sintered body. Currently, the $\mathrm{SiC}$ heat exchangers with the straight tube structure have been utilized; however more complicated structures with much larger surface area would be expected to increase the heat exchange efficiency in the near future [11], and the hollow spiral shape would be ideal for this purpose. When molding the hollow structure using the FDM-type 3D-printer, the scaffold called as the "support" is automatically inserted by the 3D-printing software. In order to make the hollow spiral structure continuous, molding under the "support-less" condition is investigated in this work. 


\section{Experimental}

In this study, the water soluble resole-type phenol resin has been chosen to prepare the liquid-state phenol resin $\mathrm{SiC}$ compound extruding from a nozzle. Because the resole-type phenolic resin has the thermosetting property, its curing rate can be adjusted by the amount of acid and heat conducted from the bed. [12]. The rheological properties of the SiC-phenol resin compound must be optimized to mold the complicated shape using this type of 3D-printer. The compound must be cured immediately after depositing by the heat flow from the bed, which would require high thermal conductivity of the $\mathrm{SiC}$ compound. To improve its thermal conductivity, the volume fraction of $\mathrm{SiC}$ in the phenol resin would be required to be as high as possible while keeping good fluidity. Also, the control of the rheological properties of the compound is essential to prevent deformation and/or drooping of the compound after extrusion. This study aims to optimize the rheological properties of the SiC-phenol resin compound for the modified FDM type 3D-printer to achieve the continuous hollow structure by examining the particle size distribution of $\mathrm{SiC}$ powders.

\subsection{D-Drawing of the Molding Body}

The 3D-drawings of the molding bodies shown in Figure 1 were created using the 3D-CAD application "SOLIDWORKS" (SOLIDWORKS Corp.). In this study, following two shapes were drawn, and were saved as the STL format.

1) An inclined cylinder with $40 \mathrm{~mm}$ outer diameter, $5 \mathrm{~mm}$ thickness, $40 \mathrm{~mm}$ height, and 60 degrees' angle.

2) A hollow spiral shape with $56 \mathrm{~mm}$ outer diameter, $20 \mathrm{~mm}$ inner diameter, $50 \mathrm{~mm}$ height, and $5 \mathrm{~mm}$ thickness. The hollow spiral was designed to have one rotation at a height of $50 \mathrm{~mm}$. In addition, the bottom surface was made flat so that the heat from the bed was conducted directly to the compound.

\subsection{Preparation of SiC-Phenol Resin Compound}

Four $\mathrm{SiC}$ powders, GC-5 $\mu \mathrm{m}, \mathrm{GC}-30 \mu \mathrm{m}, \mathrm{GC}-55 \mu \mathrm{m}$, OY-15 $\left(\mathrm{D}_{50}=0.22 \mu \mathrm{m}\right)$ (YAKUSHIMA DENKO Co., Ltd., Tokyo, Japan) were used in this work. Their particle size distributions measured using particle size analyzer (SALD-7100, SHIMADZU Corp., Kyoto, Japan) are shown in Figure 2. The particle shapes were exhibited irregular due to pulverization. A single or mixed $\mathrm{SiC}$ powder was used for preparing the $\mathrm{SiC}$-phenol resin compound.

The SiC-phenol resin compounds were prepared by mixing various volume fractions of $\mathrm{SiC}$ powder to the 95:5 mixture of resole-type phenol resin (HP3000A, ASAHI YUKIZAI Corp.) and curing agent (HA305 (35.0\% p-toluene sulfonic acid, $16.9 \%$ phosphoric acid and $48.1 \%$ Water), ASAHI YUKIZAI CORP., Tokyo, Japan). They were weighed, placed in a $200 \mathrm{ml}$ polyethylene beaker, stirred at $900 \mathrm{rpm}$ for 10 minutes, and degassed under vacuum.

\subsection{Molding Using the Modified FDM Type 3D-Printer}

In order to determine the direction of lamination, the drawings created by 

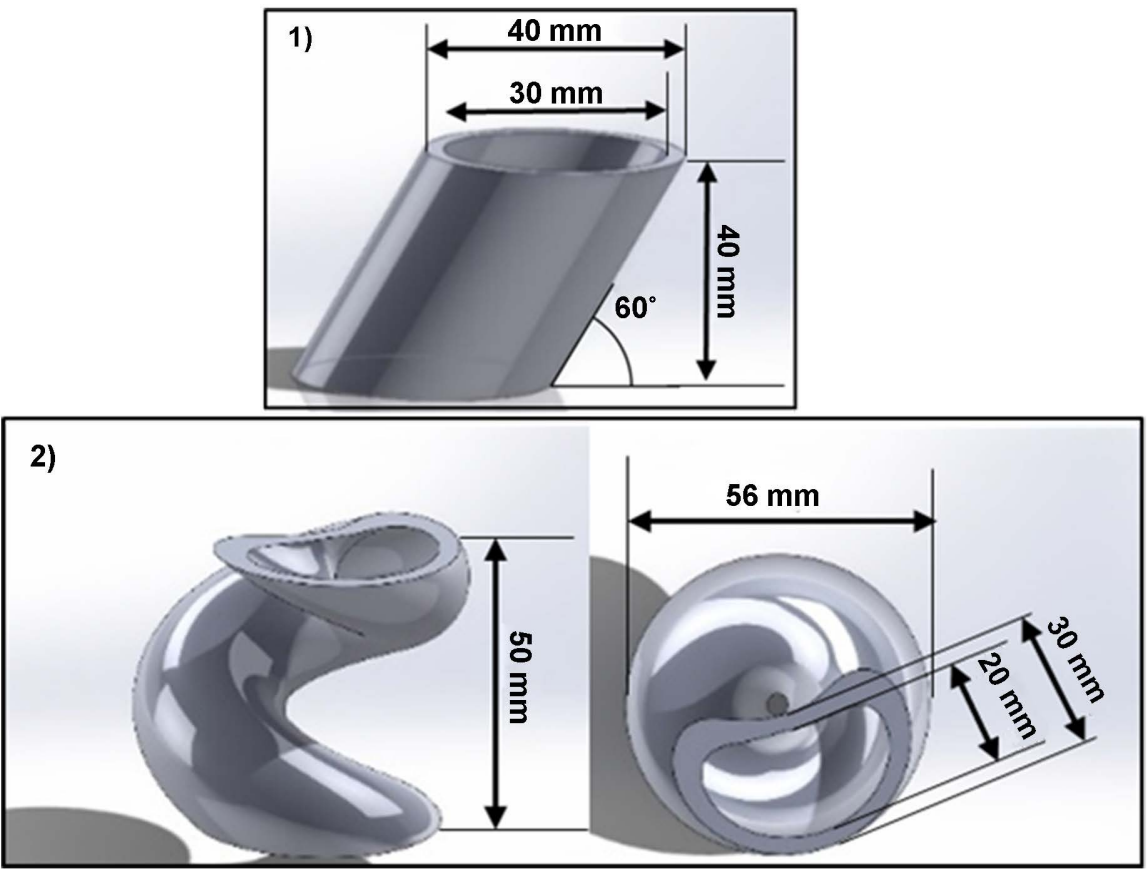

Figure 1. Shapes of molded bodies drawn by using the 3D-CAD; 1) an inclined cylinder, 2) a hollow spiral shape.

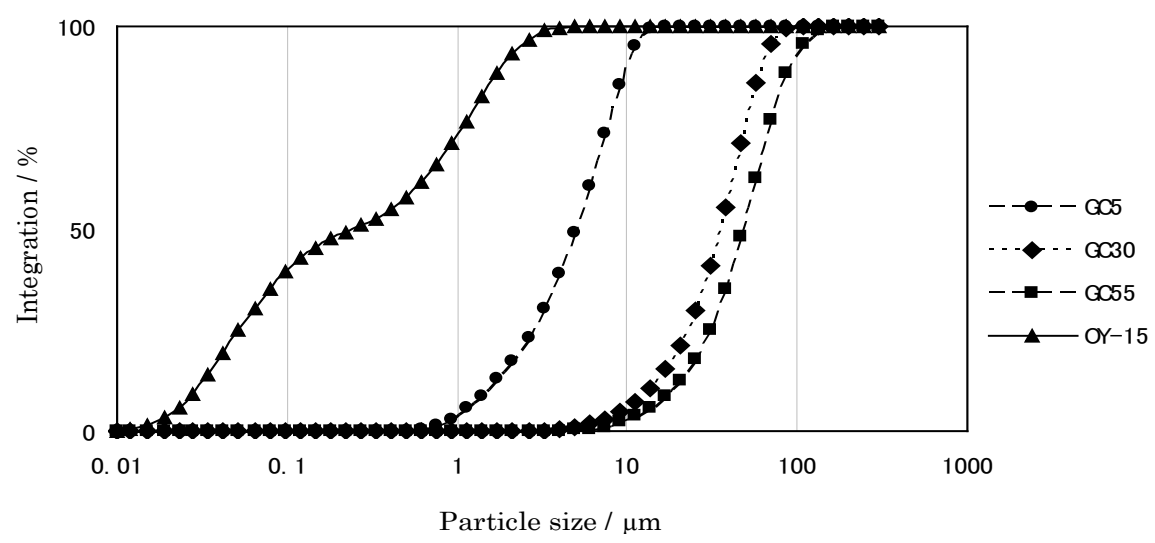

Figure 2. Particle size distribution of $\mathrm{SiC}$ powders used in this work.

3D-CAD were oriented and positioned using the "Replicator G" [13] application, and then, the file outputs were sent to the controlling PC as the STL format. The nozzle diameter, layer thickness, embedding rate, loop speed and so on were set using the "KISSlicer" [14] application and sent as the "G-code" [13]. The printing condition in this work were as follows; nozzle diameter $1.2 \mathrm{~mm}$, layer thickness $0.1 \mathrm{~mm}$, embedding rate $100 \%$, loop speed $7.40 \mathrm{~mm} / \mathrm{s}$, solid $8.48 \mathrm{~mm} / \mathrm{s}$, and sparse $13.40 \mathrm{~mm} / \mathrm{s}$. After that, the "Pronterface" [15] application was used for controlling the 3D-printers. The 3D printer "Blade-1" (Hotproceed Co., Ltd., Fukuoka, Japan) used in this study was modified to mold the liquid compounds as shown in Figure 3. After filling a plastic syringe (PSY-70E; $224.2 \times 45 \times$ $\varphi \mathrm{OD} 26.5 \mathrm{~mm}$, Musashi Engineering Inc., Tokyo, Japan) with the compound, a nozzle ((PN-16G-A; $25.5 \times \varphi \mathrm{ID} 1.26 \times \varphi \mathrm{OD} 1.65$ mm, Musashi Engineering, Inc., 


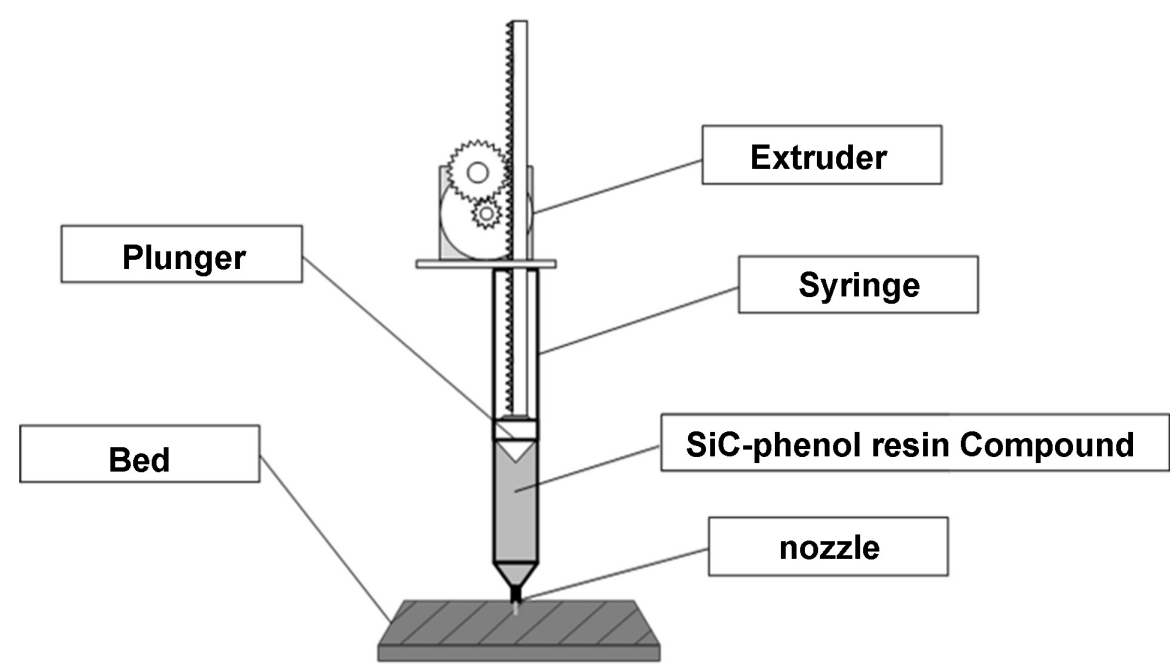

Figure 3. Schematics of the modified FDM-type 3D-printer.

Tokyo, Japan) was attached to the lower part of the syringe and a plunger (MLP-50E; Musashi Engineering, Inc., Tokyo, Japan) was attached to the upper part, and extruded using an extruder. During molding, the bed temperature was increased from $60^{\circ} \mathrm{C}$ to $140^{\circ} \mathrm{C}$ while observing the curing state of the compound.

\subsection{Rheological Properties}

The viscosities of the compounds were measured using a cone-plate type rotary viscometer (RVDV-2+Pro, AMETEK Brookfield, MA, USA) using a spindle (CPE 52). Water was used in place of the curing agent to avoid curing during measurement. The rheological properties of the compound were measured at the shear rate $1.00 \mathrm{~s}^{-1}(0.5 \mathrm{rpm})$ at $25^{\circ} \mathrm{C}$.

\section{Results and Discussion}

\subsection{Viscosities of the Compounds Containing a Single SiC Powder}

The viscosities of compounds containing a single SiC powder, OY-15 (No. 1) and GC-5 $\mu \mathrm{m}$ (No. 2), respectively, were measured first. The volume fractions of the compounds were as low as 41.6 vol.\% (65.0 wt.\%) and 41.9 vol.\% (65.2 wt.\%), respectively, above which the viscosities were almost beyond the measurement limit of the viscometer, and were found to have too high viscosity to be extruded. Since the theoretical packing ratio of close-packed cubic is about 0.74 , the mixing ratio of large and small particles $=74: 26$ would ideally fill the space, which would decrease the amount of resin. Therefore, two SiC powders with different particle sizes were mixed around this ratio to increase the volume fraction of the SiC powder, to decrease the viscosity of the compound, and hence, to increase the thermal conductivity of the compound.

\subsection{Effect of Mixing Two SiC Powders}

Table 1 (No. 3-No. 6) shows the mixing ratios of two different SiC powders, GC-30 $\mu \mathrm{m}$ and GC-5 $\mu \mathrm{m}$. The SiC volume fraction of the compound was adjusted 
Table 1. Compositions of compounds and their viscosities (1).

\begin{tabular}{ccccccccc}
\hline & \multicolumn{5}{c}{ SiC powder (\%) } & \multicolumn{4}{c}{ Composition (vol.\%) } & Viscosity \\
\cline { 1 - 2 } No. & GC55 & GC30 & GC5 & OY-15 & SiC & $\begin{array}{c}\text { Phenol } \\
\text { resin }\end{array}$ & $\begin{array}{c}\text { Curing } \\
\text { agent }\end{array}$ & (Pa.s) \\
\hline 1 & 0 & 0 & 0 & 100 & 41.6 & 55.6 & 2.8 & NA \\
2 & 0 & 0 & 100 & 0 & 41.9 & 55.4 & 2.8 & 220 \\
3 & 0 & 86 & 14 & 0 & & & & 93 \\
4 & 0 & 73 & 27 & 0 & & & & 77 \\
5 & 0 & 64 & 36 & 0 & 47.3 & 50.2 & 2.5 & 57 \\
6 & 0 & 57 & 43 & 0 & & & & 63 \\
3 & 0 & 86 & 14 & 0 & & & & 262 \\
4 & 0 & 73 & 27 & 0 & & & & 142 \\
5 & 0 & 64 & 36 & 0 & 50.0 & 47.6 & 2.4 & 179 \\
6 & 0 & 57 & 43 & 0 & & & & 271 \\
7 & 73 & 0 & 0 & 27 & & & & 139 \\
\hline
\end{tabular}

to 47.3 vol.\% (70 wt.\%). As shown in Figure 4, No. 5 had the lowest viscosity among four samples. Since the "moldability" of the compound would be balanced between low viscosity to be extruded from the narrow tip of the nozzle and high viscosity to avoid deformation after molding until curing, the SiC volume fraction was increased to $50 \%$ until obtaining a suitable moldability (No. 3 - No. 6). Then, No. 4 had lower viscosity than No. 5 as shown in Figure 4. Another set of $\mathrm{SiC}$ powders having more different mean particle diameter than the previous attempts, GC-55 $\mu \mathrm{m}$ and OY-15 $\left(D_{50}=0.22 \mu \mathrm{m}\right)$, was examined (No. 7). It was found that the mixing of GC-55 $\mu \mathrm{m}$ and OY-15 had lower viscosity than that of GC-30 $\mu \mathrm{m}$ and GC-5 $\mu \mathrm{m}$ (Table 1 ) probably due to the more efficient packing of particles.

\subsection{Molding by the "Supportless" Condition Using the Modified FDM-Type 3D-Printer}

1) An inclined cylinder

The compositions of the compounds for molding the oblique cylinders are shown in Table 2. Using the composition No. 4 and No. 7, a cylinder inclined 60 degrees were molded using the modified FDM-type 3D-printer. It was confirmed that a molded body using the composition No. 4 was completely cured. While much less steps were observed on the surface of the molded body using the composition No. 4, a lot of large "drooping" were confirmed on the surface of the molded body using the composition No. 7 as shown in Figure 5. Thus, the volume fraction of $\mathrm{SiC}$ powder in the composition No. 7 was gradually increased by $1 \%$, and a compound containing $53 \%$ volume fraction of $\mathrm{SiC}$ powder was found to have an appropriate viscosity for molding (No. 10). However, much "drooping" was still observed on its surface. 


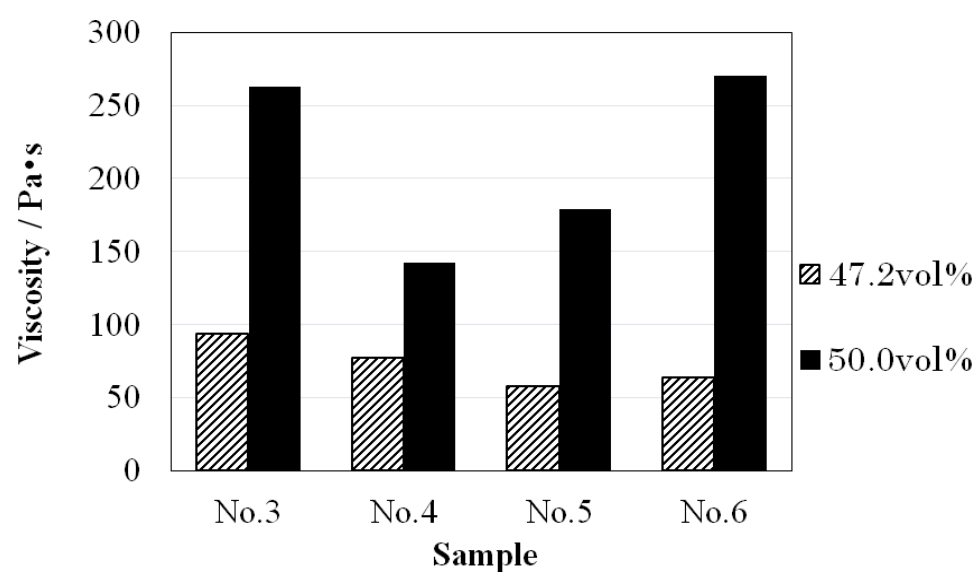

Figure 4. Viscosities of the compound No. 3, 4, 5 and 6 with 47.2 and 50.0 vol.\% of $\mathrm{SiC}$ powder varying the mixing ratio of powder with large and fine mean particle sizes.

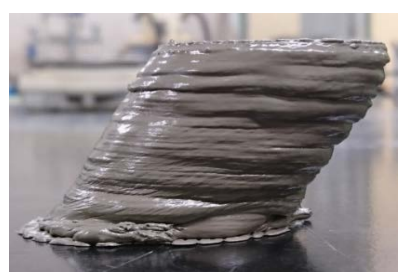

(a)

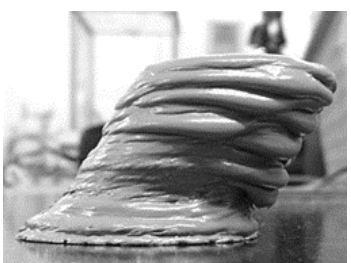

(b)

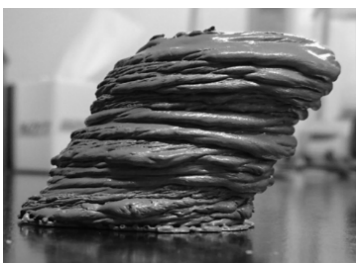

(c)

Figure 5. Appearance of the molded bodies inclined 60 degree using the compound (a) No. 4, (b) No. 7 and (c) No. 10.

Table 2. Compositions of compounds and their viscosities (2).

\begin{tabular}{|c|c|c|c|c|c|c|c|c|}
\hline \multirow[b]{2}{*}{ No } & \multicolumn{4}{|c|}{$\mathrm{SiC}$ powder $(\%)$} & \multicolumn{3}{|c|}{ Composition (vol.\%) } & \multirow{2}{*}{$\begin{array}{c}\text { Viscosity } \\
\text { (Pa.s) }\end{array}$} \\
\hline & GC-55 & GC-30 & GC-5 & OY-15 & $\mathrm{SiC}$ & $\begin{array}{c}\text { Phenol } \\
\text { resin }\end{array}$ & $\begin{array}{c}\text { Curing } \\
\text { agent }\end{array}$ & \\
\hline 4 & 0 & 73 & 27 & 0 & 50.0 & 47.6 & 2.4 & 142 \\
\hline 7 & 73 & 0 & 0 & 27 & 50.0 & 47.6 & 2.4 & 139 \\
\hline 8 & 73 & 0 & 0 & 27 & 51.0 & 46.7 & 2.3 & 397 \\
\hline 9 & 73 & 0 & 0 & 27 & 52.0 & 45.7 & 2.3 & NA \\
\hline 10 & 73 & 0 & 0 & 27 & 53.0 & 44.8 & 2.2 & NA \\
\hline
\end{tabular}

\section{2) A hollow spiral shape}

To mold the hollow spiral shape, mixtures of GC-30 $\mu \mathrm{m}$ and GC-5 $\mu \mathrm{m}$ were used because it showed better moldability. Table 3 shows the compositions for molding the hollow spiral shape. First, the same composition as No. 4 was tried, however, the upper part of a molded body was severely deformed as shown in Figure 6(a). Thus, the proportion of curing agent was increased from 5\% to $6 \%$ of the liquid component (No. 11). As a result, the molded body reached to $28 \mathrm{~mm}$ height without deformation as shown in Figure 6(b). 
Table 3. Compositions of compounds and their viscosities (3).

\begin{tabular}{|c|c|c|c|c|c|c|c|c|c|c|c|}
\hline \multirow[b]{2}{*}{ No. } & \multicolumn{4}{|c|}{ SiC powder (\%) } & \multicolumn{6}{|c|}{ Composition (vol.\%) } & \multirow{2}{*}{$\begin{array}{c}\text { Viscosity } \\
(\mathrm{Pa} \cdot \mathrm{s})\end{array}$} \\
\hline & GC-55 & GC-30 & GC-5 & OY-15 & $\mathrm{SiC}$ & $\begin{array}{c}\text { Phenol } \\
\text { resin }\end{array}$ & $\begin{array}{c}\text { Curing } \\
\text { agent }\end{array}$ & Methanol & Water & Nanosilica & \\
\hline 11 & 0 & 73 & 27 & 0 & 50.0 & 47.2 & 2.8 & - & - & - & NA \\
\hline 12 & 0 & 73 & 27 & 0 & 52.0 & 40.7 & 2.5 & 4.8 & - & - & NA \\
\hline 13 & 0 & 73 & 27 & 0 & 50.0 & 37.7 & 2.3 & - & 10.0 & - & NA \\
\hline 14 & 0 & 73 & 27 & 0 & 50.0 & 46.6 & 2.8 & - & - & 0.6 & NA \\
\hline 15 & 0 & 73 & 27 & 0 & 50.0 & 41.9 & 2.5 & 5.0 & - & 0.6 & NA \\
\hline 16 & 0 & 73 & 27 & 0 & 50.0 & 37.2 & 2.2 & - & 10.0 & 0.6 & NA \\
\hline
\end{tabular}

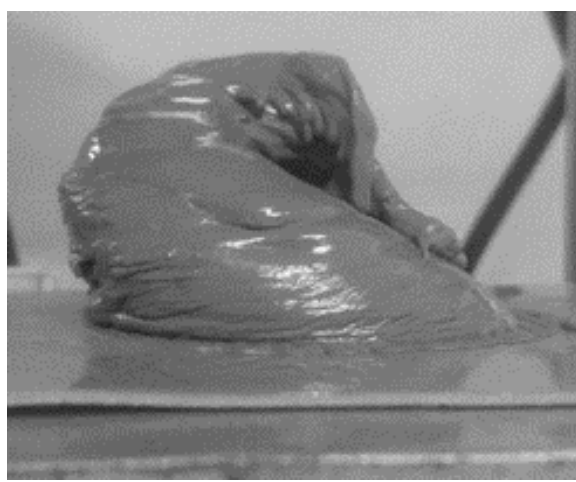

(a)

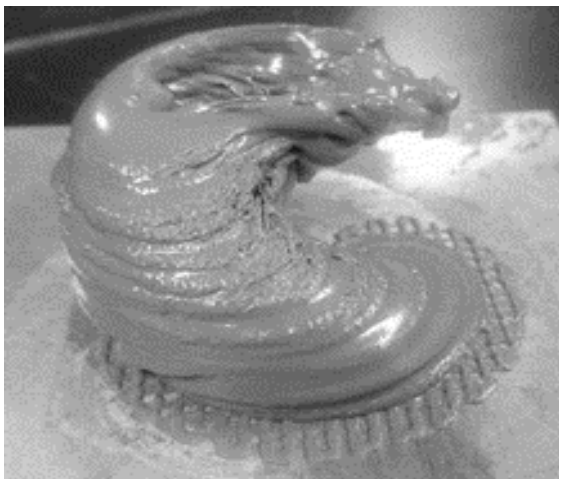

(b)

Figure 6. Appearance of the molded bodies with hollow spiral shape using the composition (a) No. 4 and (b) No. 11.

In order to improve the moldability of the compound during extrusion and to promote the increase of viscosity during heating, volatile medium such as methanol or water was added as shown in Table 3. When methanol was added, the $\mathrm{SiC}$ volume fraction was improved to $52 \mathrm{vol. \%}$ (No. 12), and it was observed that a molded body had a smooth surface. However, the molded body deformed before reaching to $30 \mathrm{~mm}$ height even though raising the bed temperature up to $140^{\circ} \mathrm{C}$ as shown in Figure 7(a). When additional water was added to the phenol resin HP3000A (the resin concentration $70 \mathrm{wt}$ \% typical) to decrease the resin concentration to $56 \mathrm{wt} . \%$ (No. 13), the molded body reached to $50 \mathrm{~mm}$ height without deformation as shown in Figure 7(b). The reason why hardening of the methanol added system did not work would be considered that the polymerization reaction was inhibited by adding methanol because the thermal functional group of the resole type phenol resin was a methylol group, $-\mathrm{CH}_{2} \mathrm{OH},-\mathrm{CH}_{2} \mathrm{O}$, and so on as shown in Figure 8 [12].

To suppress deformation after molding, thixotropy was imparted to the compound by adding "nanosilica" (ADMANANO YA010C, Admatechs Co. Ltd.). When as low as 0.6 vol.\% of nanosilica was added (No. 14), it was possible to mold up to $48 \mathrm{~mm}$ height. As expected, thixotropy was imparted due to the addition of very fine particles, which would attract each other by the Van der 


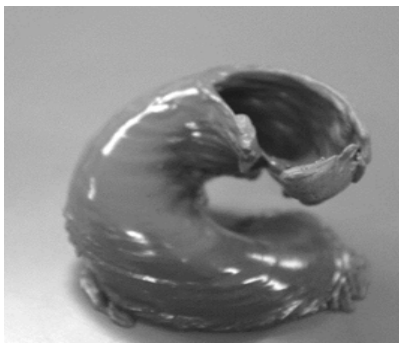

(a)

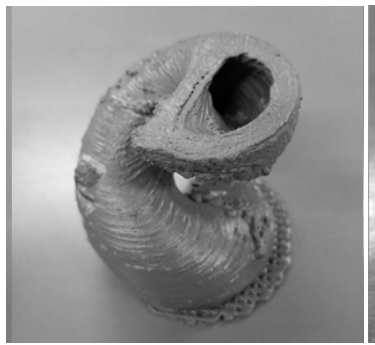

(b)

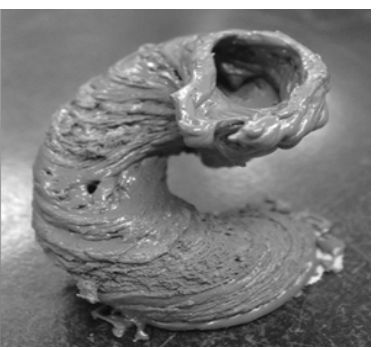

(c)

Figure 7. Appearance of the molded bodies with hollow spiral shape using the composition (a) No. 12, (b) No. 13 and (c) No. 14.<smiles>OCc1cc(CO)c(O)c(Cc2cc(Cc3ccccc3O)cc(CO)c2O)c1</smiles>

Figure 8. Representative structure of resole type phenol resin.

Waals force to form the chain structure that would make the molded body maintain its shape until curing. However, much more "drooping" was observed comparing to the methanol added and water added systems as shown in Figure 7 (c). Thus, moldings were carried out using the methanol + nanosilica addition (No. 15) and the water + nanosilica addition (No. 16). In the case of the methanol + nanosilica addition, a molded body reached to $35 \mathrm{~mm}$ height without deformation, and many steps due to lamination were clearly observed on the surface as shown in Figure 9(a), which was noticeably deferent from the smooth surface of the methanol-added system. In the case of the water + nanosilica addition, the molded body reached to $50 \mathrm{~mm}$ height without deformation as shown in Figure 9(b).

Finally, all dimensions of hollow spiral molding body were reduced by $20 \%$, which reduced the volume by $48.8 \%$, so that the molding time also became much shorter. As shown in Figure 10(b), the nanosilica addition significantly reduced "drooping", and thus, it was possible to produce molded bodies with much fewer defects, which would be suitable for molding more complicated shapes.

\subsection{Rheological Properties}

The flow curves of the compounds No. 11 (without nanosilica) and No. 14 (with nanosilica) were characterized by a rheometer (MCR 302, Anton Paar GmbH, Graz, Austria) using a parallel plate device ( $25 \mathrm{~mm}$ diameter). Shear rate was increased and decreased between 0.01 and $10 \mathrm{~s}^{-1}$ in 20 seconds at $25^{\circ} \mathrm{C}$. Figure 11(a) and Figure 11(b) show their rheological behaviors. Both compounds showed a shear thinning behavior. The viscosity of the compound No. 14 was higher than that of the compound No. 11, simply because the powder content in 


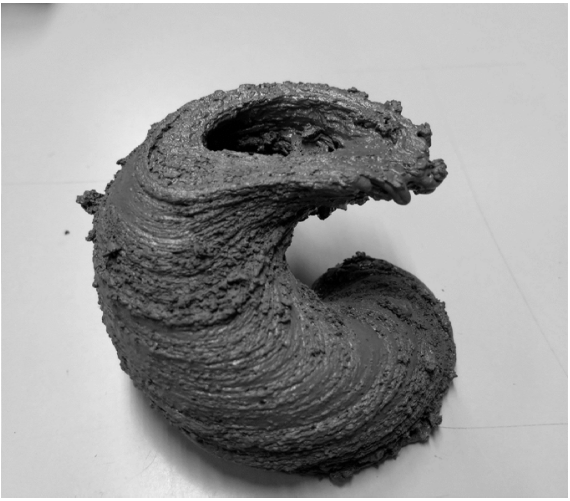

(a)

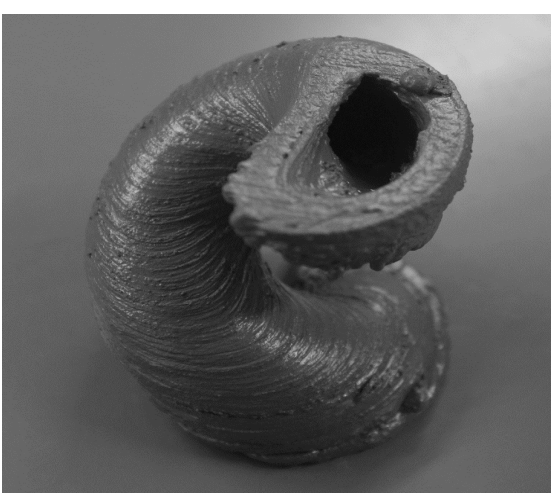

(b)

Figure 9. Appearance of the molded bodies with hollow spiral shape using the composition (a) No. 15 (methanol + nanosilica) and (b) No. 16 (water + nanosilica).

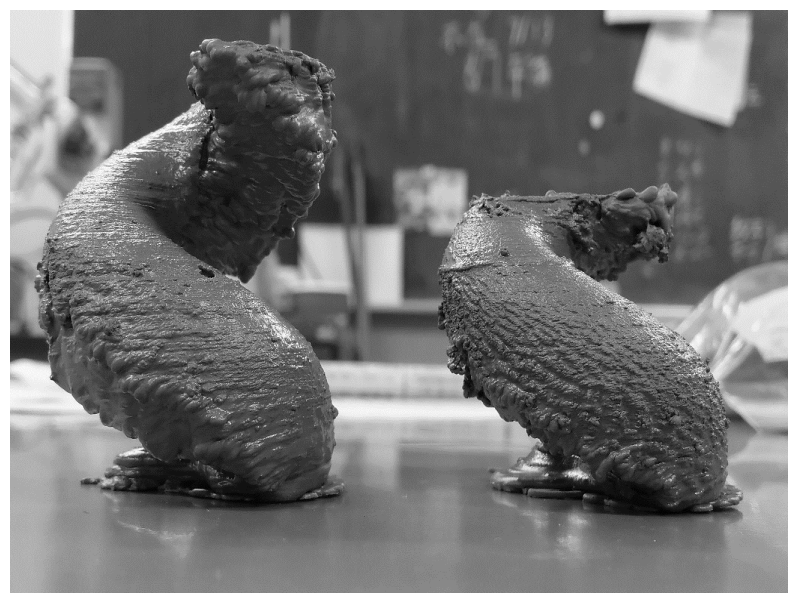

Figure 10. Appearance of the molded bodies with $20 \%$ reduced hollow spiral shape using the composition. No. 7 (diluted by water) and No. 16 (water + nanosilica).

the compound No. 14 was higher than that of the compound No. 11. Because the shear rate of extrusion from the nozzle was calculated to be $5.6 \mathrm{~s}^{-1}$, the viscosity of the compound No. 14 was about 500 Pa.s while the shear rate was increasing, and $330 \mathrm{~Pa} \cdot \mathrm{s}$ while decreasing. On the other hand, the viscosity of the compound No. 11 was about $330 \mathrm{~Pa} \cdot \mathrm{s}$ while the shear rate was increasing, and $230 \mathrm{~Pa} \cdot \mathrm{s}$ while decreasing. Shear stress-shear rate curves shown in Figure 11(b) clearly demonstrates much more thixotropy in the compound No. 14 than in the compound No. 11, which would be caused by aggregated fine particles of nanosilica, and would contribute to maintain the molded shape to $48 \mathrm{~mm}$ height without "drooping" until curing.

\section{Conclusions}

The FDM-type 3D-printer modified for using a liquid compound was developed to mold the complicated structure using the SiC-phenol resin compound. To fabricate the continuous hollow spiral structure, the "support-less" condition must 


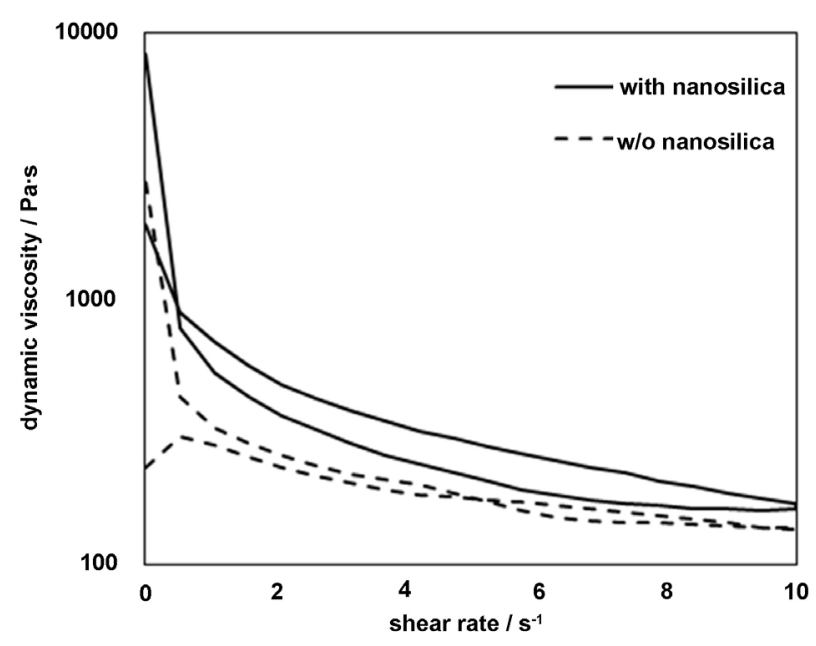

(a)

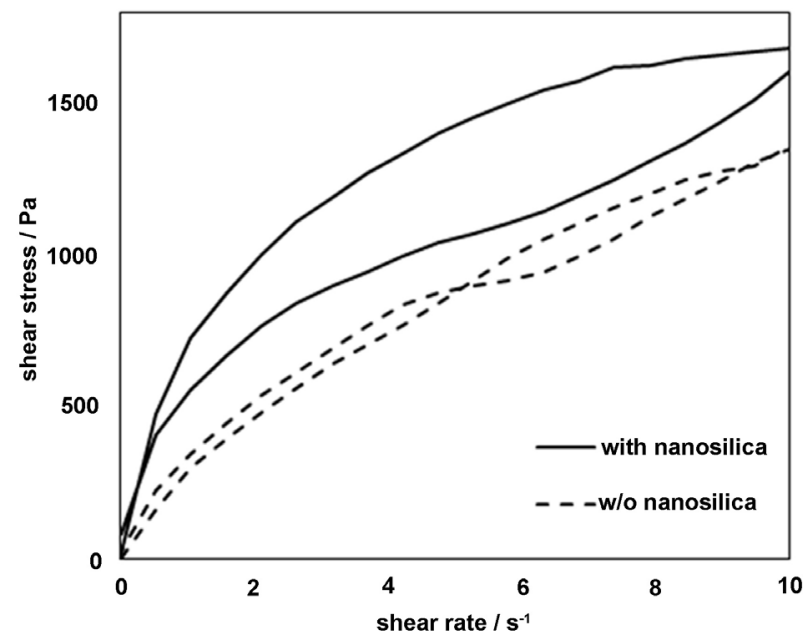

(b)

Figure 11. Rheological properties of the composition No. 11 (without nanosilica) and No. 14 (with nanosilica); (a) Dynamic viscosity vs. shear rate, and (b) Shear stress vs. shear rate.

be achieved. For this purpose, extruded SiC-phenol resin compounds must be cured by heat flow from the bed immediately after molding to keep the molded shapes. To improve the thermal conductivity of the compound, the particle size distribution of $\mathrm{SiC}$ powder was optimized by mixing two $\mathrm{SiC}$ powders with large and fine mean particle sizes, so that the volume fraction of $\mathrm{SiC}$ increased up to $53 \mathrm{vol. \%}$ (75 wt.\%), while those of the compound using a single SiC powder were limited to about 42 vol.\%.

Combined with the addition of water that vaporized after molding to increase the compound viscosity, and the addition of nanosilica that imparted the thixotropy to the compound, $\mathrm{SiC}$ molded bodies with the continuous hollow spiral structure were successfully fabricated, which would enable us to manufacture high performance heat exchangers with much lower cost by using the FDM-type 3D-printer than those by using the P-3DP techniques, and further, to mold the SiCand other types of ceramics with complicated shapes that would be impossible to manufacture due to the difficulty for discharging the unused powder inside the hollow molded body.

\section{Acknowledgements}

The authors gratefully thank Prof. Mizui at Kyushu Kyoritsu Univ. for his contribution modifying the FDM type 3D printer used in this work.

\section{Conflicts of Interest}

The authors declare no conflicts of interest regarding the publication of this paper.

\section{References}

[1] Suyama, S., Kameda, T. and Itoh, Y. (2003) High-Strength, Reaction-Sintered Sili- 
con Carbide Ceramic. Toshiba Review, 58, 46-49.

[2] Kimura, T., Miura, H. and Goto, T. (2017) Development of Direct Additive Manufacturing Technique for Ceramics Using Laser Irradiation. Bulletin of the Ceramic Societyof Japan, 52, 692-695.

[3] Suyama, S., Itoh, Y., Kohyama, A. and Katoh, Y. (2001) Development of High Strength Reaction-Sintered Silicon Carbide. Journal of the Ceramic Society of Japan, 109, 315-321. https://doi.org/10.2109/jcersj.109.1268_315

[4] Yano Research Institute Ltd. (2013) FY2013 Survey on Actual Condition of Manufacturing Base Technology (Survey of Technical Strategy Formulation Base of Fine ceramics Industry). Tokyo, 60-88.

[5] Zocca, A., Colombo, P., Gomes, C.M. and Gunster, J. (2015) Additive Manufacturing of Ceramics: Issues, Potentialities, and Opportunities. Journal of the American Ceramic Society, 98, 1983-2001. https://doi.org/10.1111/jace.13700

[6] Deckers, J., Vleugels, J. and Kruth, J.-P. (2014) Additive Manufacturing of Ceramics: A Review. Journal of Ceramic Science and Technology, 5, 245-260.

[7] BroschureIntrinSiC—Schunk Carbon Technology (2018). http://www.schunk-carbontechnology.com/fileadmin/Redakteur/Carbon_Technolo gy/Broschueren/BU6/SchunkCarbonTechnology-IntrinSiC-en.pdf

[8] Allahverdi, M., Danforth, S.C., Jafari, M. and Safari, A. (2001) Processing of Advanced Electroceramic Components by Fused Deposition Technique. Journal of the European Ceramic Society, 21, 1485-1490. https://doi.org/10.1016/S0955-2219(01)00047-4

[9] Cesarano III, J. (1999) A Review of Robocasting Technology. Proceedings of Materials Research Society Symposium, 542, 133-139.

[10] Kunpeng, C., Benito, R.-M., Smay, J.E., Zhou, J., Osendi, M.I., Belmonte, M. and Miranzo, P. (2012) Geometrically Complex Silicon Carbide Structures Fabricated by Robocasting. Journal of the American Ceramic Society, 95, 2660-2666. https://doi.org/10.1111/j.1551-2916.2012.05276.x

[11] Scheithauer, U., Schwarzer, E., Moritz, T. and Michaelis, A. (2018) Additive Manufacturing of Ceramic Heat Exchanger: Opportunities and Limits of the Lithography-Based Ceramic Manufacturing (LCM). Journal of Materials Engineering and Performance, 27, 14-20. https://doi.org/10.1007/s11665-017-2843-z

[12] Inatomi, S. (2013) Recently Progress of Phenolic Resins. Journal of Network Polymer Japan, 34, 45-53.

[13] G Codes-ReplicatorG (2018). http://replicat.org/gcodes

[14] KISSlicer-Home (2018). http://www.kisslicer.com/

[15] (2018) Printrun: Pure Python 3D Printing Host Software. http://www.pronterface.com/ 